\title{
Vozes esquecidas: a defesa do meio ambiente no Brasil dos séculos XVIII e XIX
}

\author{
Forgotten voices: the defense of the environment in \\ Brazil in the eighteenth and nineteenth centuries
}

\author{
Arthur Soffiati \\ Professor da Universidade Federal Fluminense (UFF) \\ soffiati@censa.com.br
}

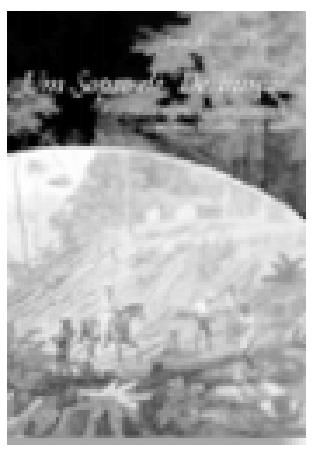

José Augusto Pádua Um sopro de destruição: pensamento politico e crítica ambiental no Brasil escravista (17861888)

Rio de Janeiro, Jorge Zahar, 2002, 318p.
C erca de cinqüenta autores escreveram em torno de 150 textos que José Augusto Pádua usou como fontes primárias para escrever um livro inédito na produção de história e de ciência política no Brasil: Um sopro de destruição: pensamento político e crítica ambiental no Brasil escravista (1786-1888). Na verdade, trata-se da bem cuidada tese de doutoramento de Pádua, agora apresentada sob forma de livro de acessível leitura, sem jamais abrir mão do rigor da pesquisa acadêmica.

Logo no princípio, o autor reconhece quatro grandes visões de natureza. A primeira desvaloriza a natureza não-humana - não se incomodando com sua destruição, quer por indiferença ou pela desqualificação - , ao considerar a natureza tropical inferior à temperada. Esta concepção foi mais vivida que pensada no Brasil pelo pragmatismo dos proprietários rurais, apenas interessados em extrair do ambiente o máximo que ele pudesse lhes render. A segunda reconhece a importância da natureza não-humana, mas a considera um obstáculo ao pleno desenvolvimento das antropossociedades. A terceira tece loas à natureza não-humana, mas entende a sua destruição como um ônus a ser pago pelo país que deseja se desenvolver. Pádua aponta o poema 'O ermo', de Bernardo Guimarães, como exemplo desta postura. A quarta, típica do romantismo, louva intensamente a natureza, mas não se engaja em qualquer luta política para defendê-la.

Pádua identifica uma quinta atitude nos autores que arrola e investiga. Eles não apenas apregoaram a necessidade de proteger a natureza não-humana frente ao progresso econômico e social, como também asseguraram que esta proteção era indispensável ao desenvolvimento. Para estes autores,

O meio natural foi elogiado por sua riqueza e potencial econômico, sendo sua destruição interpretada como um signo de atraso, ignorância e falta de cuidado. O verdadeiro progresso supunha a conservação e o uso correto do mundo natural que, por sua vez, só fazia sentido no contexto desse progresso. A natureza era vista como um objeto político, um recurso essencial para o avanço social e econômico do país (pp. 27-8).

Em suma, na visão destes pensadores, que construíram uma tradição intelectual esquecida, só se podia pensar o desenvolvimento com respeito à natureza, enquanto esta era condição sem a qual o Brasil não lograria um nível de progresso que o inserisse no concerto das nações. 
Mas Pádua deixa bem claro, logo de início, o caráter minoritário deste grupo intelectual no contexto brasileiro de uma economia predatória, ao mesmo tempo que, comparando a produção desses homens com a que se criou em outros países, ele se vê diante de uma tradição extremamente fecunda e progressista.

\section{Contemplação e ação}

Não houve, no Brasil dos séculos XVIII e XIX, quem visse a natureza pelo seu valor intrínseco, a exemplo de Rousseau e de Thoreau, que adotavam atitude de contemplação diante dela e desprezavam a idéia de progresso e de desenvolvimento. No caso dos pensadores estudados por Pádua, havia um denominador comum bem claro:

Esse denominador comum foi essencialmente político, cientificista, antropocêntrico e economicamente progressista. Em suma, profundamente enraizado no ideário iluminista herdado do século XVIII ... Os pensadores aqui analisados, de maneira geral, não defenderam o ambiente natural com base em sentimentos de simpatia pelo valor intrínseco, seja em sentido estético, ético ou espiritual, mas sim devido à sua importância para a construção nacional. Os recursos naturais constituíam o grande trunfo para o progresso futuro do país, devendo ser utilizados de forma inteligente e cuidadosa. A destruição e o desperdício dos mesmos eram considerados uma espécie de crime histórico, que deveria ser duramente combatido ... esses autores não escrevem a partir de iniciativas isoladas, mas sim como parte de um grupo bastante coerente em suas características intelectuais e sociais (p. 13).

O grupo em questão tem suas raízes fincadas na Universidade de Coimbra, depois da reforma por que passou em 1772, e na Academia Real de Ciências de Lisboa, fundada em 1799. Ambas instituições eram pólos de irradiação da ilustração. Além delas, havia um grande mestre inspirador: o consagrado naturalista italiano Domenico Vandelli, entusiasta do estudo da natureza para fins econômicos, desde que respeitada o que se denominava economia da natureza. Cabe não esquecer também a figura de Rodrigo de Sousa Coutinho, ministro da Marinha e do Ultramar, entre 1796 e 1801, homem ilustrado que apoiou o projeto de um desenvolvimento com respeito à natureza.

\section{Pragmatismo e intelectualismo}

O primeiro olhar do europeu português sobre a natureza nãohumana nas terras do futuro Brasil percebeu um vasto reservatório de recursos que poderiam ser explorados para alimentar uma economia de mercado que já marchava a passos largos na Europa. Tratava-se de uma visão pragmática e utilitarista que forjou a concepção de uma natureza inesgotável, impossível de ser dissipada e capaz de gerar riquezas em caráter ilimitado ao país invasor e colonizador. A princípio, os europeus encontraram dificuldades em lidar com ecossistemas tão estranhos e pujantes. No continente-mãe, as comportadas florestas temperadas tinham sido muito reduzidas e os rios apresentavam dimensões modestas. 
Nas novas terras, rios, como o Amazonas, o Parnaíba, o São Francisco e o da Prata, eram apavorantes pelo volume d'água. As florestas tropicais assustavam por sua luxúria. Pouco a pouco, porém, foram eles dominando o ambiente que se lhes mostrava hostil e colocando-o sob seu domínio para retirar-lhe os recursos que alimentavam uma economia mercantil e monetária.

Para tanto, lançaram mão do fogo, já conhecido dos povos indígenas, de modo a suprimir rapidamente as formações vegetais nativas. Queimavam-se florestas inteiras para a implantação de monoatividades agrícolas e pastoris com procura no mercado europeu, sem a mínima preocupação de proteger o necessário para a manutenção dessa economia perdulária. A síndrome da inesgotabilidade levava ao desperdício. Para aumentar a lucratividade dessa economia, o acesso à terra tornou-se fácil aos homens livres e detentores de um certo grau de poder, através do instituto das sesmarias, grandes glebas distribuídas gratuitamente. Para completar o quadro, empregou-se o trabalho do africano capturado e vendido como escravo. Essa economia rude e predatória produziu homens igualmente rudes e insensíveis em relação à natureza tropical e aos escravos. Esses homens embrutecidos no trato com uma economia tão primária não dispunham de tempo para pensar sobre suas práticas produtivas ou, mais que isso, não tinham interesse em reflexões desta ordem. Nem sequer tinham qualquer consciência do que estavam fazendo para registrar por escrito suas concepções de natureza e de economia. Quando muito, seus registros restringiam-se a apontamentos de contabilidade.

A análise e a crítica dessa economia rústica e predatória, que vivia da fartura dos recursos naturais, foi efetuada pelos filhos dos que conseguiram acumular dinheiro suficiente para enviá-los a estudar na Europa, principalmente em Lisboa e em Paris. Vários pais esperavam que seus filhos pudessem se preparar para assumir seus negócios. Mas, em vários casos, o efeito se assemelhava à trajetória de um bumerangue: os filhos se tornavam críticos implacáveis do modelo pragmático de economia praticado no Brasil.

Assim, Pádua mostra que o grupo de pensadores brasileiros influenciados pelo iluminismo propunha não uma atitude contemplativa frente à natureza. Tampouco, seus integrantes endossavam as práticas econômicas que permitiram, em grande parte, a construção de uma visão crítica, segundo a qual o desenvolvimento situava-se a meio caminho entre o romantismo e o pragmatismo rude praticado por seus pais. Sem abandonar o antropocentrismo e o pragmatismo, eles propunham um desenvolvimento com proteção da natureza nativa, não como compensação para uma atitude preservacionista, mas por defenderem com sinceridade e ardor o desenvolvimento como fator de construção de uma nova nacionalidade. Na explicação de Pádua,

A grande novidade apresentada pelos primeiros críticos ambientais brasileiros foi a de produzir uma espécie de metacrítica do progresso ... apesar de condenar a falta de progresso e defender esse último como um valor político superior, eles não aceitaram a idéia de que todas as atividades produtivas 
ou processos de expansão social, inclusive todas as inovações tecnológicas pudessem ser enquadradas em seu bojo... Não se tratava de uma crítica da modernidade e dos males do crescimento por si mesmos ..., mas sim de uma crítica interna ao universo moderno que, com base nas próprias premissas deste último, denunciava a realidade brasileira como uma espécie de farsa do avanço civilizatório, uma ordem calcada em instituições técnicas herdadas do atraso colonial ... Não se tratava de negar as ferrovias e outros elementos do mundo moderno, mas sim de questionar as conseqüências de superpôlas a uma realidade socioeconômica rudimentar e predatória (p. 27).

Assim, estes pensadores não faziam uma crítica radical da modernidade, que nem sequer ganhara o estatuto de conceito, mas propondo uma via mais progressista da modernidade que pudesse ultrapassar o contexto atrasado de seus pais.

É oportuno notar o diálogo de surdos que se instalou entre os praticantes da economia predatória e seus críticos. Os segundos conheciam com detalhes o modelo que criticavam. Os primeiros, todavia, não conseguiam compreender o que lhes assacavam os letrados. Duas passagens, especialmente, ilustram este abismo entre ambos. Manoel Jacinto de Sampaio e Melo, ex-aluno de Coimbra que se estabeleceu como dono de engenho de açúcar na Bahia, escreveu, em 1816, um livro intitulado Novo método de fazer açúcar e tentou colocar em prática suas idéias. Considerado um estranho entre os outros, ele confessa que apelidaram seu engenho de "engenho da filosofia" e que the dedicaram versos satíricos (p. 113).

No Congresso Agrícola convocado em 1878 pelo ministro da Agricultura, Comércio e Obras Públicas, João Lins de Cansansão de Sinimbu, ouviu-se a voz dissonante de Manoel Ribeiro do Val, lavrador em Paraíba do Sul, troar sobre o caráter dilapidador da agricultura brasileira e sobre a necessidade de proteger as florestas. Nenhum dos presentes lhe deu a menor atenção, pois os interesses deles eram pragmáticos e imediatistas, como de resto se observa ainda hoje (p. 255).

\section{Ruralismo e industrialismo}

Outro aspecto da mais alta relevância percebido por Pádua em sua investigação: a quase totalidade desta "ilha de letrados num mar de analfabetos", que chegou a exercer, em certo momento, alguma influência sobre a elite governante brasileira, inclusive sobre Pedro II, entendia que o desenvolvimento do Estado nacional brasileiro deveria seguir a trilha da economia rural, e não a da industrialização. Conquanto constituíssem um grupo de pensadores progressistas, suas idéias de desenvolvimento não negavam a tradição econômica do país. A vertente fisiocrata revelava-se neles como um timbre gravado a fogo. Os mais expressivos nomes desta tradição, como José Gregório de Moraes Navarro, José Joaquim da Cunha de Azeredo Coutinho, Manoel Arruda Câmara, Baltasar da Silva Lisboa, José Bonifácio de Andrada e Silva, Emílio Joaquim da Silva Maia, Januário da Cunha Barbosa, Antonio Muniz de Sousa, Francisco Freire Alemão Cisneiros, José de Saldanha 
da Gama e tantos outros, inserem-se mais na linha de François Quesnay que de Adam Smith.

Pouquíssimos autores mencionados no livro de Pádua aventaram o progresso do Brasil passando pela industrialização. Extemporânea parece ser a irrupção de uma passagem da Memória sobre a capitania de Minas Gerais, publicada por José Vieira Couto em 1799. A certa altura, como que escapulindo da tradição ruralista, ele exclama:

Parece-me que já vejo um novo horizonte, um novo céu: milhares de fornalhas cobrem as planícies, que levantam espessos rolos de fumo às nuvens. Os montes já são minados, e por uma boca estreita vomitam as suas ricas entranhas. O estrondo de mil máquinas fere os meus ouvidos, um povo laborioso, contente e alegre cobre em bandos a superfície da terra (pp. 115-6).

Pádua, no entanto, apressa-se em explicar que a visão otimista de Viera Couto quanto ao industrialismo não deriva propriamente de uma experiência vivida por ele, senão de uma imagem "idealizada e desencarnada do mundo industrial, que provavelmente seria modificada se o autor tivesse a oportunidade, que outros tiveram, de observar diretamente o impacto da cidade industrial européia sobre o meio ambiente" (p. 116). A meu juízo, trata-se de uma avaliação discutível, por duas razões. Primeiramente, torna-se difícil, para não dizer impossível, supor qual seria a visão de Vieira Couto, caso ele tivesse vivido a experiência de conhecer uma região industrializada da Inglaterra no final do século XVIII. A miséria, as péssimas condições de vida e a poluição, àquela altura ainda localizadas, poderiam ser consideradas superáveis e um preço a pagar pelo progresso. Segundo, mesmo por via indireta, o conhecimento que Vieira Couto adquiriu do industrialismo não deve ser desconsiderado em seu vislumbre do caminho que o Brasil deveria seguir.

Seja como for, o pensamento industrialista, nos marcos do exame empreendido por Pádua, está confinado a poucos pensadores e ao efêmero surto de industrialização e urbanização em torno da personalidade de João Evangelista de Souza, o barão de Mauá. Também Joaquim Nabuco não deixa de incluir a industrialização nas cidades como um dos instrumentos de destruição da obra da escravidão (p. 273). Aliás, sente-se a falta daqueles que defenderam a industrialização no Brasil no estudo do autor, ainda que a natureza não-humana tenha sido calada em seus escritos. Por outro lado, o livro de Pádua não deixa margem a dúvidas sobre o caráter progressista daqueles que conceberam projetos políticos para o Brasil tomando por base o mundo rural. Destaco este traço como uma das maiores contribuições da obra, visto que ele propõe rediscutir o tema da industrialização no Brasil, tão presente na historiografia brasileira, e sugere uma revisão da pecha de conservadorismo que recaiu sobre pensadores como Alberto Torres e Luís Amaral, para só citar dois nomes mais eminentes, no século XX. 


\section{Com escravo e sem escravo}

Embora as concepções dos pensadores estudados por Pádua apresentassem impressionante unidade, ele registra diferenças significativas a separá-los. Uma delas dizia respeito ao papel representado pela escravidão no atraso da economia. Os maiores expoentes desta tradição, como Baltasar da Silva Lisboa, José Bonifácio de Andrada e Silva, André Rebouças e Joaquim Nabuco, responsabilizavam a escravidão pelo estado primitivo da agricultura e defendiam abertamente a sua superação de modo reformista. Por outro lado, havia quem acreditasse na ultrapassagem do caráter predatório das atividades rurais com a manutenção da escravidão. Esta a posição de José Joaquim da Cunha de Azeredo Coutinho, que chegava mesmo a considerar a escravidão como um indício de progresso. Pádua ensaia uma classificação mais relativizada dos pensadores sobre a escravidão:

O grande diferencial do abolicionismo ... não esteve no plano da retórica. O passo radical foi o de estabelecer uma relação de causalidade forte entre o escravismo e o caráter decadente, atrasado e destrutivo da vida socioeconômica brasileira ... A primeira posição ignorava, ou pelo menos não explicitava em seus textos escritos, o tema da escravidão, culpando a ignorância e a ineficiência tecnológica pela destruição ambiental. É o que podemos encontrar em Freire Alemão e Guilherme Capanema. A segunda posição abordava de forma explícita e crítica o tema da escravidão, mas sem reconhecer a existência de uma relação causal forte entre esta última e a destruição ambiental. A escravidão e a degradação do território eram vistas como fenômenos paralelos, que compartilhavam o mesmo caráter atrasado e a mesma origem colonial. Essa identidade no anacronismo fazia com que ambas devessem desaparecer no mesmo movimento, sendo superadas pelo processo de modernização e racionalização do país. É a postura típica de vários analistas de assuntos agrícolas, como Nicolau Moreira e Miguel Silva. A terceira posição, inaugurada por José Bonifácio e retomada por André Rebouças e Joaquim Nabuco, vinculou diretamente a superação do trabalho servil e da cultura da destruição ... Foi sempre através da análise crítica da agricultura, aliás, desde os seus primeiros delineamentos em Vandelli e Baltasar da Silva Lisboa, que a interface entre o escravismo e a degradação do território pôde ser detectada. Daí a importância de examinar ambos os temas conjuntamente (p. 264).

Seria até possível dividir a história desta tradição em três fases. A primeira, que começa em fins do século XVIII e se estende até a colossal obra de José Bonifácio, explicitamente relacionando a destruição do ambiente à escravidão. A segunda, nas décadas de 1830 e 1840, acreditando na conciliação de uma economia rural moderna com a escravidão ou evitando discuti-la. Por fim, a terceira, a partir da década de 1850 até 1888, voltando a criticar de forma acerba a escravidão como a causa maior da situação retrógrada do Brasil. Os campeões do terceiro momento são, sem dúvida, André Rebouças e Joaquim Nabuco. Este não se contentava em condenar a escravidão. Era preciso destruir também tudo que a ela se relacionava, como o latifúndio e a monocultura mercantil. De resto, José Bonifácio também defendia estas idéias. 
No pensamento econômico, social, político e historiográfico brasileiro, continua vigorando ou uma animosidade com relação ao meio ambiente ou uma indiferença indisfarçável. Os cientistas sociais continuam vendo a natureza não-humana como palco para o drama humano. No máximo, ela entra, em suas reflexões, como variável. Mas o meio ambiente não pode ser visto como algo que se subtrai ou se acrescenta numa análise. Ele é uma constante em relação à qual se adota uma postura meramente instrumental ou uma atitude que considera seus limites. Os pensadores estudados por Pádua inseremse nesta segunda tradição, prefigurando o que hoje está muito em voga com o nome de desenvolvimento sustentável.

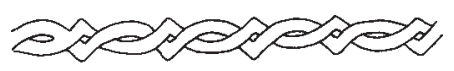

